\title{
Views of Students of Kwame Nkrumah University of Science and Technology
} Dental School on Dentistry as a Career

Alexander O Acheampong ${ }^{1 *}$, Merley A Newman-Nartey², Patrick C Ampofo ${ }^{3}$, Robert N Larmie ${ }^{4}$, Nana T Ampem-Gyimah ${ }^{4}$, James A Amoateng ${ }^{5}$, Francis Adu-Ababio ${ }^{5}$ and Peter Donkor ${ }^{1}$

${ }^{1}$ Department of Oral and Maxillofacial Sciences, Kwame Nkrumah University of Science and Technology Dental School, Ghana, West Africa

${ }^{2}$ Department of Orthodontics and Pedodontics, University of Ghana School of Medicine and Dentistry, College of Health Sciences, University of Ghana, Ghana, West Africa

${ }^{3}$ Department of Restorative Dentistry, University of Ghana School of Medicine and Dentistry, College of Health Sciences, University of Ghana, Ghana, West Africa

${ }^{4}$ Oral and Maxillofacial Unit, Komfo Anokye Teaching Hospital, Ghana, West Africa

${ }^{5}$ Department of Community Dentistry, Kwame Nkrumah University of Science and Technology Dental School, Ghana, West Africa

\section{Abstract}

Background: Career choice is a critical decision that has an obvious impact on the future life pattern of an individual. Understanding the priorities and socio-demographic background of students choosing dentistry is essential because economic factors may influence an individual's level of commitment to the profession.

Aim/Objective: The aim of this study was to evaluate factors that influenced the current group of dental students to accept to pursue Dentistry as an undergraduate programme from Kwame Nkrumah University of Science and Technology (KNUST) dental school.

Materials and Methods: This is a cross-sectional study of KNUST dental students carried out from January to March 2017. The complete student population was 215 which included 25 foreign students and thus there was no sampling. A structured Google form questionnaire was designed and submitted to students through their respective class representatives. The data collected included reasons for their choice of the program of Dentistry and the factors that influenced their decision.

Results: A total of 160 responded out of the total student's population of 215 . This represented $74.4 \%$ of the total student population. The average age was 23.4 years. And the male to female ratio was $1: 1.3 .75 \%$ of the respondents had been to a dental clinic before. $51(31.9 \%)$ chose dentistry as their first choice. About $23 \%$ of the students reported they ended up in dentistry due to their non-acceptance into the medical school. $20 \%$ of the students said that they had no prior knowledge of dentistry and $50 \%$ of the students indicated that Dentistry was not their first option because there was no government financial sponsorship for students opting for dentistry at the KNUST dental school as compared to the Medical program.

Conclusion: Dentistry was not the preferred program choice among dental students from KNUST. Majority of them ended up in Dentistry because of their non-admission into Medical school. Only $31.9 \%$ chose dentistry as their first preference. The majority who chose it as their first choice had had previous positive encounters with dental surgeons. Other students made the decision based on advice from relatives or due to their belief that the profession was lucrative or had flexible working hours.

Keywords: Career; Dentistry; Choice; Students; Perspective

\section{Introduction}

Dentistry is a branch of medicine that deals with the diagnosis and the care of orofacial pathologies. The choice of career by students is determined by a complexity of factors and dentistry is not an exception.

Career choice is a critical decision that has an obvious impact on the future life pattern of an individual. Understanding the priorities and socio-demographic background of those choosing dentistry is essential because economic factors may influence the individual's level of commitment to the profession The interesting aspect is the extent to which societal changes influence the choice of dentistry [1]. Career choice is generally influenced by advice from parents, relatives, teachers, friends and even counselors. However, variations occur from one population to the other [2]. In developed countries like Finland [3], United Kingdom [4], and the United States [2], talking to relatives or friends in the dental profession was the most influential factor. The quality of applicants for dental schools, judged by grade point averages and Dental Admissions Test scores, was reported as being high in the USA [2].

Research undertaken to explore the reasons for choosing dentistry as a career in developed countries showed that Ireland [5] perceived ease of employment, being self-employed, working regular hours, good income and the opportunity to help people were the most significant motives for joining the profession. In contrast, in the USA, selfemployment and business-related motives were observed to be the main reasons for choosing the specialty [6].

In a study conducted at the University of Benghazi [7], Libya, Dentistry was the first choice for $78.6 \%$ with no significant sex difference. Helping people was given the maximum score by the students followed by the scientific factor as the reason for choosing dentistry. Females appeared to be significantly influenced by their high grades in high schools compared to males.

${ }^{*}$ Corresponding author: Alexander O Acheampong, Department of Oral and Maxillofacial Sciences, Kwame Nkrumah University of Science and Technology Dental School, Ghana, West Africa, Tel: 233543289; E-mail: aotiacheampong@yahoo.com

Received February 26, 2019; Accepted March 06, 2019; Published March 13, 2019

Citation: Acheampong AO, Newman-Nartey MA, Ampofo PC, Larmie RN, Ampem Gyimah NT, et al. (2019) Views of Students of Kwame Nkrumah University of Science and Technology Dental School on Dentistry as a Career. Dentistry 9: 536 doi:10.4172/2161-1122.1000536

Copyright: ㄷ 2019 Acheampong AO, et al. This is an open-access article distributed under the terms of the Creative Commons Attribution License, which permits unrestricted use, distribution, and reproduction in any medium, provided the original author and source are credited. 
Citation: Acheampong AO, Newman-Nartey MA, Ampofo PC, Larmie RN, Ampem-Gyimah NT, et al. (2019) Views of Students of Kwame Nkrumah University of Science and Technology Dental School on Dentistry as a Career. Dentistry 9: 536. doi:10.4172/2161-1122.1000536

Page 2 of 4

In another study to determine career choice among Moroccan [8] students indicated that dentistry had a noble function; the "desire to help people" and "job opportunities" were the leading factors that influenced their decision.

In a study carried out in Nigeria [1], the vast majority of Nigerian dental students (97\%) qualified for dental school based on their performance at the University Matriculation Examination. About onethird, 32.5\%, indicated that dentistry was their first choice for a career. This choice was greatly influenced by family in $50 \%$ of this group of students.

There were several factors that strongly influenced career choice among students who indicated that dentistry was their first choice in the above study: interest, prestige, good employment opportunity abroad, and regular work hours.

The need to is a member of a prestigious and financially lucrative profession comparable to medicine were the commonest reasons identified by the group of students for whom dentistry was not the first career choice. The motives for choosing dentistry as a career in this group of students seemed to relate to an image of dentistry as a vehicle for the achievement of personal goals [1]. The field of Dentistry in Ghana is seen to be mainly associated with tooth extractions and is comparatively unknown by most Ghanaians. The aim of this study was to evaluate the factors that influenced dental students to accept to pursue dentistry as an undergraduate programme from KNUST dental school.

\section{Materials and Method}

A descriptive cross-sectional study was conducted among 215 KNUST dental students (which included 25 foreign students from January to March 2017. The current student population was 215 including 25 foreign students. A structured Google form questionnaire was designed and submitted to students through their respective class representatives. The data collected included motives for their acceptance to pursue dentistry, their preferred choice programme and factors influencing this decision. Respondents were informed of the objectives of the study and that participation was voluntary and anonymous. They were asked to provide written consent to participate in the study prior to completing the questionnaire.

The various year group class representatives were identified and contacted. The Google form link was emailed to these representatives who in turn forwarded the link to their classmates. The questionnaire was filled online and submitted as requested. There were some openended questions which required non-structured responses. The submitted responses were summarized, categorized and analyzed.

\section{Statistical analysis}

The data were compiled by the authors into Microsoft Excel sheet. Descriptive statistics and qualitative analysis were used to evaluate the students' views of their choice of dentistry a career.

\section{Results}

\section{Data collection and analysis}

Out of the total student population of 215, 160 students submitted the questionnaire online giving a response rate of $74.4 \%$. The age range was from 19 to 28 years. The average age was 23.4 years. And the male to female ratio was $1: 1.3$.

\section{Experience of participants of visiting a dental surgeon prior to starting the dental program}

Prior to starting the program, $75 \%$ of the respondents had visited a dental surgeon while $25 \%$ of the students had not.

\section{Factors associated with participants studying dentistry}

Dentistry was the first-choice program of the majority of participants $(\mathrm{n}=51,31.9 \%)$ followed by the participants who opted for the program due to their non-admittance into their first-choice program of Medicine ( $\mathrm{n}=36,22.5 \%)$.

The least number of participants did not choose the program at all but opted for it after it was offered to them by the University $(n=6$, $3.8 \%$ ) (Table 1).

\section{Motivation for dentistry being participants first choice program $n=51$}

With regards to participants who chose dentistry as their firstchoice program, their primary motivation of the majority $(n=25,49 \%)$ was from the personal encounter with a dental surgeon followed by participants who received advice from parents or relatives. The least number of participants' motivation was from guidance counseling and the prospect of a lucrative career with flexible working hours $(\mathrm{n}=8$, $15.6 \%$ ) each (Table 2).

\section{Motivation for dentistry NOT being participants' first choice program}

The most common factor for participants first choice program not being dentistry was due to its being more expensive program than medicine, followed by their belief that it was not as prestigious

\begin{tabular}{|l|c|c|}
\hline $\begin{array}{l}\text { Factors associated with participants } \\
\text { studying dentistry }\end{array}$ & Frequency & Percentage (\%) \\
\hline My first choice & 51 & 31.9 \\
\hline Did not get admitted into the medical program & 36 & 22.5 \\
\hline My second choice & 24 & 15 \\
\hline My third and fourth choice & 24 & 15 \\
\hline Did not choose dentistry at all & 10 & 6.3 \\
\hline Dentistry is a health-related programme & 9 & 5.6 \\
\hline Not my choice but offered to me by KNUST & 6 & 3.8 \\
\hline TOTAL & $\mathbf{1 6 0}$ & $\mathbf{1 0 0}$ \\
\hline
\end{tabular}

Table 1: Factors associated with participants studying dentistry $(n=160)$.

\begin{tabular}{|l|c|c|}
\hline $\begin{array}{l}\text { The motivation for the choice of dentistry being } \\
\text { participants first choice program }\end{array}$ & Frequency & $\begin{array}{c}\text { Percentage } \\
\text { (\%) }\end{array}$ \\
\hline A personal encounter with a dentist & 25 & 49 \\
\hline Advice from parents/relatives & 10 & 19.6 \\
\hline Through guidance counseling & 8 & 15.7 \\
\hline \multirow{2}{*}{ Lucrative with flexible working hours } & 8 & 15.7 \\
\cline { 2 - 3 } & 51 & 100 \\
\hline
\end{tabular}

Table 2: Motivation for Dentistry being participants first choice program $(n=51)$

\begin{tabular}{|l|c|c|}
\hline NOT being a participants' first choice program & Frequency & Percentage (\%) \\
\hline Dental program expensive & 43 & 39.4 \\
\hline Not as prestigious as medicine & 20 & 18.3 \\
\hline Did not know much about dentistry & 20 & 18.3 \\
\hline Want to be called a 'doctor' instead of a 'dentist' & 15 & 13.8 \\
\hline Limited job opportunities & 6 & 5.5 \\
\hline Less lucrative & 5 & 4.6 \\
\hline TOTAL & $\mathbf{1 0 9}$ & $\mathbf{1 0 0}$ \\
\hline
\end{tabular}

Table 3: Motivation for dentistry not being participants first choice program $(n=109)$. 
as medicine and ignorance of the profession $(n=20,18.3 \%)$ each. The forth-most common reason was that the participants wanted the title of 'doctor' rather than 'dentist' (Table 3).

\section{Discussion}

The professional socialization of dental surgeons begins with admission to dental school and continues throughout the entire study period. In this study, there were more females than males at the KNUST dental school different from the USA study where females, account for over half of all applicants and enrollees [9].

For the majority of the current students in the KNUST dental school, dentistry was not their first choice. This obviously is different from what pertains in developed countries where dentistry [5,9] is the preferred choice by most students. Even in the subregion of Nigeria [1], the choice of dentistry was high among their good science students. About a third of the participants in this current study chose dentistry as their second to fourth preference. Another interesting phenomenon was that about $23 \%$ of the respondents reported they ended up in dentistry due to their non-admission to medical school. This demonstrates that the majority of our students could be studying dentistry by default and not due to their true interest in the profession. This default placement in the dentistry programme has the tendency to affect morale and the career satisfaction of dental students. This could lead to poor academic performance and psychological insecurity because students would have a tendency towards an inferiority complex regarding their medical colleagues. In a study carried out in Nigeria [1], $32.5 \%$, indicated that dentistry was their first choice of a career. This choice was greatly influenced by family in $50 \%$ of this group of students. There were several factors that strongly influenced career choice among students who indicated that dentistry was their first choice in the above study: interest, prestige, good employment, opportunity abroad, and regular work hours. This finding from the Nigerian study is different from our current study which demonstrated that; the majority of our current students did not consider dentistry to be a prestigious career. In a related study from Brazil [10], results demonstrated that the choice of occupation was made primarily for economic reasons, followed by vocational reasons, professional reasons and personal reasons.

The need to go into a prestigious and financially lucrative profession similar to medicine was the commonest reasons identified by the group of students for whom dentistry was not the first career choice [1]. The motives for choosing dentistry as a career in this group of students seem to relate to an image of dentistry as a vehicle for the achievement of personal goals.

Further probing in this current study indicated that out of the $37 \%$ that chose dentistry as their first choice, the majority of them did so because they had a positive encounter with a dentist, advice from family members and support from career guidance and the fact that dentistry is lucrative. This is similar to other related studies in Finland and Ireland $[1,5,8,11]$.

Even though from this study only $25 \%$ of the participants had never visited a dentist, it was possible that those who visited the dentist did not receive a positive image from the encounter. Until recently, the majority of the procedures by dental surgeons in Ghana were tooth extractions which are associated with pain and blood. It is possible that the students do not want to be associated with the tag of "tooth extractors and pain inflictors'. Among those who did not choose dentistry as their first choice, the reasons were:

1. Dentistry was less prestigious compared to medicine

\section{There were fewer job opportunities}

\section{They wanted to be called 'doctor' instead of 'dentist'}

Majority of respondents who did not choose dentistry as their first choice of the study indicated that they had no previous knowledge of the profession (13.8\%) or it was because dentistry was expensive at KNUST (39.4\%). It was considered expensive because there is no quota for government-sponsored students.

From the above analysis, it appears that the reason for not choosing dentistry was multifactorial including, poor perception, cost, and lack of education about dentistry at the first and second cycle schools. Most prospective students were not aware of the program, though it was less lucrative with fewer job opportunities and yet was more expensive.

This perception in our view will not encourage academically good students to choose dentistry unless they have had a good insight into the prospects of dentistry. Good students may not even have the resources to pay the fees and therefore would not even choose the program. Lack of information on the profession would also have students end up choosing the program as the next best option as seen in this study where some students did not choose dentistry at all but were offered the program by the university admission team.

\section{Recommendations}

Ghana currently has a population of over 26 million with just about 275 dentists to service the entire population. KNUST dental school which was started about a decade ago has trained 100 dental surgeons as of December 2017.

School curricula should address the importance of good oral health and its role in the overall health of the individual. The importance of regular visits to the dental surgeon should be stressed.

There should be increased exposure to dentistry especially in our communities where a wide range of procedures is offered to clients to promote a positive image of the responsibilities of a dental surgeon at the community level. There should be outreach programs by dental students and dental societies into schools from primary to senior schools to educate students and treat patients in a friendly environment to encourage the students' interest in dentistry.

KNUST dental school should organize periodic career workshops together with the guidance and counseling teams in secondary schools to showcase the duties of a dental surgeon to encourage increased interest in the profession and enable students to make an informed choice of dentistry as a career.

KNUST dental school should take a second look at the strict feepaying policy to enable students who qualify academically but are financially deprived to be admitted and not be limited to studying dentistry at the University of Ghana School of Medicine and Dentistry that has a limited government-sponsored student quota.

Faculty should periodically engage the current dental students to educate them on the career job prospects since the majority of them are nonetheless still quite ignorant on this issue to motivate the students to give off their best and enhance their academic performance. In Africa, the dentist to population ratio is approximately 1:150000 against about 1:2000 in most industrialized countries. Ghana needs more dental surgeons to take care of its growing population and improve upon its dentist population ratio. 
Citation: Acheampong AO, Newman-Nartey MA, Ampofo PC, Larmie RN, Ampem-Gyimah NT, et al. (2019) Views of Students of Kwame Nkrumah University of Science and Technology Dental School on Dentistry as a Career. Dentistry 9: 536. doi:10.4172/2161-1122.1000536

Page 4 of 4

\section{Conclusion}

Dentistry was not the preferred choice of the undergraduate program among dental students from KNUST. Majority of them ended up in dentistry because of non-admission to medical school. Only $31.9 \%$ choose dentistry as their first choice. Majority of those whose chose it as their first choice had had positive previous encounters with dental surgeons, were advised to make the choice by relatives and in addition because the profession is lucrative with flexible working hours. Those who did not choose Dentistry as the preferred program of choice indicated that it was expensive, less prestigious than medicine with fewer job opportunities.

It is important for stakeholders in the health sector to instruct students of the importance of good oral health in the overall health of an individual and the role of the dental surgeon in achieving this objective.

\section{Declarations}

Ethics approval and consent to participate

Not applicable

Consent for publication

Not applicable

Availability of data and materials

Data can be obtained from the corresponding author upon request.

\section{Competing interests}

The authors declare that there is no conflict of interest that might bias the outcome of the paper.

\section{Funding}

This study did not receive a specific grant from the funding agencies.

\section{Authors' contributions}

All authors have contributed adequately to be included as authors.

It was the belief of the least number of participants that it was less lucrative than medicine $(n=5,4.6 \%)$ followed by the participants who believed it was a career in which there were limited job opportunities.

\section{References}

1. Orenuga $\mathrm{OO}$, da Costa $\mathrm{OO}$ (2006) Characteristics and study motivation of clinical dental students in Nigerian universities. J Dent Educ 70: 996-1003.

2. Weaver RG, Haden NK, Valachovic RW (2000) U.S. dental school applicants and enrollees: A ten year perspective. J Dent Educ 64: 867-874.

3. Eli I, Judes H, Allerhand-Alexander Y (1988) Dentists and dentistry: Attitude changes toward the chosen profession. Hum Relat 41: 929-937.

4. Bedi R, Gilthorpe MS (2000) Ethnic and gender variations in university applicants to United Kingdom medical and dental schools. Br Dent J 189: 212-215.

5. Hallissey J, Hannigan A, Ray N (2000) Reasons for choosing dentistry as a career-A survey of dental students attending a dental school in Ireland during 1998-99. Eur J Dent Educ 4: 77-81.

6. Scarbecz M, Ross JA (2002) Gender differences in first-year dental students' motivation to attend dental school. J Dent Educ 66: 952-961.

7. Bourzgui F, Abidine Z, Serhier Z, Diouny S, Bennani Othmani M (2014) Motivational factors influencing career choices of Moroccan dental students. Oral Health Dent Manag 13: 390-394.

8. Wanchek T, Cook BJ, Anderson EL, Duranleau L, Booker C (2015) U.S. Denta school applicants and enrollees, 2014 entering class. J Dent Educ 79: 1373-1382.

9. Aguiar CM, Pessoa MA, Câmara AC, Perrier RA, de Figueiredo JA (2009) Factors involved in the choice of dentistry as an occupation by pernambuco dental students in Brazil. J Dent Educ 73: 1401-1407.

10. Vigild M, Schwarz E (2001) Characteristics and study motivation of Danish dental students in a longitudinal perspective. Eur J Dent Educ 5: 127-133.

11. WHO Oral Health Services. Available from: http://www.who.int/oral_health/ action/services/en/ Accessed on: July 08, 2018. 